giving four molecules of $\mathrm{SnSb}$ per unit cell as required by a sodium chloride lattice.

The arrangement of atoms into a sodium chloride type lattice would indicate that the compound is ionic in character. This requires the tin to be trivalent. From formulæ given by Pauling (J.Amer. Chem. Soc., 49 , p. $765 ; 1927$ ) the calculated ionic radii for $\mathrm{Sn}^{+3}$ and $\mathrm{Sb}^{-3}$ are respectively 0.75 and $2.45 \mathrm{~A}$., which when built up into a sodium chloride structure, gives a lattice constant $6.40 \mathrm{~A}$., in poor agreement with the observed value. However, the atomic radii for tin and antimony for co-ordination number 8 are 1.53 and 1.56 respectively (Goldschmidt ; Trans. Faraday Soc., 25 , p. $253 ; 1929$ ), and for co-ordination number 6 , these are reduced to 1.484 and $1.513 \mathrm{~A}$. Such radii would give a lattice constant of 5.99 , in good agreement with the experimental value $6.092 \mathrm{~A}$.

The structure of $\mathrm{SnSb}$ is found to persist over the range 46 to 60 per cent tin with some change of lattice constant, showing that both tin and antimony are soluble in it. This agrees with the equilibrium diagram given by Broniewski and Sliwowski (Comptes rendus, 186 , p. 1615 ; 1928), although they thought a compound $\mathrm{Sn}_{3} \mathrm{Sb}_{2}$ existed at the end of this range-at 60 per cent tin. Our X-ray analysis, however, shows that the compound is definitely $\mathrm{SnSb}$ with a range of solid solution on either side. The solution of tin and antimony by the compound can be readily understood, since both metals have acidic and basic properties. In addition, their atomic numbers and atomic dimensions are practically the same, so that one atom of tin could be replaced by one of antimony, and vice versa. The solution of antimony up to 4 per cent causes a change of lattice constant from 6.092 to $6 \cdot 106 \mathrm{~A}$. Before annealing, the solution of 10 per cent tin causes a definite expansion to $6 \cdot 124 \mathrm{~A}$., but after annealing there is no measurable change.

A microphotograph due to Dr. J. E. Stead (J. Inst. Metals, 22, p. 127; 1919) shows excellent cubic crystals of SnSb. Many of them were observed to be perfect cubes, having angles of $90^{\circ}$ at each corner. The crystals have also been observed as the hard constituent of tin-base bearing metals.

A full account of the investigation of the crystal structures of the complete system is to appear elsewhere.

Physics Department,

University College, Swansea, Nov. 5.

W. Morris Jones. E. G. Bowen.

Cause of High Winds of Oct. 19-20, 1917.

THE remark on p. 633 of NATURE of Oct. 18 (Historic Natural Events, Oct. 19, 1920) that, "Owing to the unexpected development of a barometric depression . . . a very strong cold north-east wind sprang up at some height above the ground ", does not state the facts correctly and gives a misleading impression of the cause of the high winds at an altitude of $10,000-20,000 \mathrm{ft}$. on the occasion in question.

The winds at those heights over south-east England and northern France on Oct. 19-20, 1917, were northerly and not north-easterly. These winds occurred over a region where the horizontal gradient of pressure was insignificant at sea-level. This insignificant gradient, however, became a steep west to east gradient at great heights owing to the fact that there was a steep horizontal gradient of temperature in the upper air also from west to east. The strong northerly wind was simply a thermal wind. Generally, the actual wind is compounded of the thermal wind and the wind arising from the horizontal gradient of pressure at sea-level. On this occasion, as the latter was practically nil, the actual wind was practically coincident with the thermal wind.

A reasonably complete account of the conditions at the time is given in Vol. 4 of Shaw's "Manual of Meteorology ", p. 112, along with the explanation of the phenomenon. I find on looking up my records that I gave the facts and the explanation to the General Staff at G.H.Q., France, on Oct. 23, 1917.

8 Hurst Close, London, N.W.11,

E. GoLD. Oct. 24.

CoL. Gold is no doubt fundamentally correct as to the cause of the high winds of Oct. 19-20, 1917. My version agrees with that in McAdie's book, "Man and Weather", p. 12, which runs: "But a depression developed in the Atlantic, west of the British Isles, and the light variable winds, characteristic of settled fair weather, were routed quickly by cold north or north-east winds of 20 metres or more per second. The airships from midnight until 7 A.M. were carried south and somewhat east, at a speed of fifty miles an hour." A closer examination of the facts, however, shows that this view of the mechanism is too superficial.

The Writer of the Note.

\section{Scientific Inexactitude.}

In Nature of Nov. 8 , p. 725, Mr. Darling criticises a certain sentence in a recent book on "Sound". The sentence in question, "A clamped steel bar electrically maintained is sometimes employed as a rough standard of frequency", is described as "unfortunate' and 'incorrect', and is given as an example of a tendency towards scientific slang.

Mr. Darling is, in effect, suggesting that all statements must be explicit in every detail, nothing must be implied. The sentence to which he refers is taken from a section entitled "Transverse vibrations of elastic bars" and from a sub-section commencing (24 lines away) "Electromagnetic methods of maintenance of the vibrations". One might reasonably expect, therefore, that even "a reader not conversant with the subject" would understand that the words " in vibration" are implied after the word "maintained" in the sentence quoted. I consider his alternatives "operated" or "driven" no better than the word actually used.

If all statements were explicit and nothing implied, a scientific book, or any other class of book, would make very dull reading. Mr. Darling's method applied to such well-known expressions as " an oscillating circuit', 'a reversing switch ', 'a projector screen.', and so on, would lead to extremely laboured and amusing English. Abbreviation is essential to progress, provided that it is not carried beyond the intellectual limits of the reader, and I consider that the abbreviation in the sentence Mr. Darling quotes is entirely justified.

Applying his views to the opening sentence of his letter, what does Mr. Darling mean exactly when he says "a reader ... may be completely fogged"? Presumably he does not really mean the reader is fogged any more than the sentence quoted means that the tuning fork is maintained ? Again, what is an "unfortunate sentence"? The English language is based on such 'slang'.

"Beaumont", Hampton Hill, A. B. WooD.

No. 3187 , VoL. 126]

$$
\text { Nov. } 13 .
$$

